Academic Platform Journal of Engineering and Science

journal homepage: http://apjes.com/

\title{
Şev Stabilitesi Probleminin Geri Analizle Çözümü: Örnek Bir Vaka
}

\author{
${ }^{* 1}$ Buse Ün, ${ }^{2}$ Abdulazim Yildız \\ ${ }^{1}$ İskenderun Teknik Üniversitesi, İnşaat Mühendisliği Bölümü, buseun.mfbe19@iste.edu.tr \\ ${ }^{2}$ Çukurova Üniversitesi, İnşaat Mühendisliği Bölümü, abdulazim.yildiz@gmail.com
}

Araştırma Makalesi

Geliş Tarihi: 21.05.2020

Kabul Tarihi: 26.11.2020

$\ddot{O} \mathbf{z}$

$\mathrm{Bu}$ çalışmada bir şev stabilitesi problemi incelenmektedir. Şev üzerinde bir yol güzergâhı bulunmaktadır ve şevin göçme potansiyeli yüksektir. Bu çalışmanın amacı, şevde güvenlik analizinde kullanılan programların tutarlılığının incelenmesi ve şev hareketini önleyecek tasarımın belirlenmesidir. Bu amaçla, ilk olarak, şevin topoğrafik özellikleri belirlenmiş ve mevcut duruma ait model oluşturulmuştur. Şev modeline ait verileri elde etmek için arazi ve laboratuvar çalışmalarından faydalanılmıştır. Geri analiz yöntemi kullanılarak kayma yüzeyine ait parametreler elde edilmiştir. Mevcut durumu yansıtan model üzerinde, şevi güvenli hale getirecek tasarım oluşturulmuştur. Analizler; sonlu elemanlar yöntemini esas alan Plaxis 2D (2018) ve limit denge yöntemlerine dayanan Slide V.6.0. programları ile gerçekleştirilmiştir. Sonuç olarak, güvenlik analizi hesabında kullanılan programlardan uyumlu sonuçlar elde edilmiştir. Ele alınan şev stabilitesi probleminde, iyileştirme yöntemi olarak fore kazıkla destekleme uygun görülmüştür. Ek olarak drenaj yöntemleri ile yüzey sularının uzaklaştırılması önerilmiştir.

Anahtar Kelimeler: Şev stabilitesi, Vaka analizi, Geri analiz, Ağırlık yüklemesi

\section{Solution of the Slope Stability Problem by Back Analysis: An Example Case}

\author{
*1Buse Un, ${ }^{2}$ Abdulazim Yildiz \\ ${ }^{1}$ Iskenderun Technical University, Department of Civil Engineering, buseun.mfbe19@iste.edu.tr (iD \\ ${ }^{2}$ Cukurova University, Department of Civil Engineering, abdulazim.yildiz@gmail.com
}

\begin{abstract}
In this study, a slope stability problem is investigated. There is a road route located on the slope and the slope has a high potential to failure. The purpose of this study is to examine the consistency of programs used in slope safety analysis and to determine the design that will prevent slope movement. For this purpose, firstly, topographic features of the slope were determined and then a model of the current state was created. Field and laboratory studies were used to obtain the data of slope model. Parameters of the failure surface were obtained by using back analysis method. Afterwards, a design that will make the slope safe was created on the model which reflects the current state. Analysis was performed by using both Plaxis 2D (2018), which is based on finite element method, and another program called Slide V.6.0. based on limit equilibrium methods. As a result, compatible results were obtained from the programs used in the safety analysis calculation. In the slope stability problem discussed, supporting with bored pile was considered appropriate as an improvement method. In addition, it was proposed to remove surface waters by drainage method.
\end{abstract}

Keywords: Slope stability, Case study, Back analysis, Gravity loading

\section{GİRIŞ}

İklim, doğa olayları ve yeni yapıların yapılması gibi etkenler topoğrafyanın doğal yapısını değiştirmektedir. Arazilerin doğal yapısının değişmesi stabilite problemlerine neden olmaktadır. Nüfusun artmasıyla birlikte eğimli (şevli) arazilere; konut, yol vb. yapıların kontrolsüz bir şekilde yapılması, şevlerde stabilitenin bozulmasına neden olmuş ve heyelan vakalarını arttırmıştır. Ülkemizde ve dünyada şev stabilitesi problemleri için uygun önlem alınmadığında büyük kayıplar yaşandığı görülmüştür. Heyelan vakasının yaşandığı yerlerden edinilen bilgiler, durumun ciddiyetini 
ortaya koymaktadır. Şekil 1'de görüntüsü bulunan, 2010 yılında Tayvan'da meydana gelen heyelan, ciddi kayıplara neden olmuştur [1]. 2017 yılında Çin'de meydana gelen bir heyelan vakasında 100'den fazla kişi ve yaklaşı 60 ev toprak altında kalmıştır [2]. Ülkemizde 1990 yılında şiddetli yağış neticesinde Maçka/Çatak'da meydana gelen heyelanda 65 kişi hayatını kaybetmiş ve trilyonlarca liraya varan maddi zarar ortaya çıkmıştır [3]. Yaşanan vakalarda görüldüğü gibi heyelan; milli servetlerin yok olmasına, büyük oranda can ve mal kayıplarına neden olabilmektedir. $\mathrm{Bu}$ sebepten heyelanın değerlendirilmesi ve heyelanın vereceği zararlara karşı uygun önlemlerin alınması son derece önemlidir.

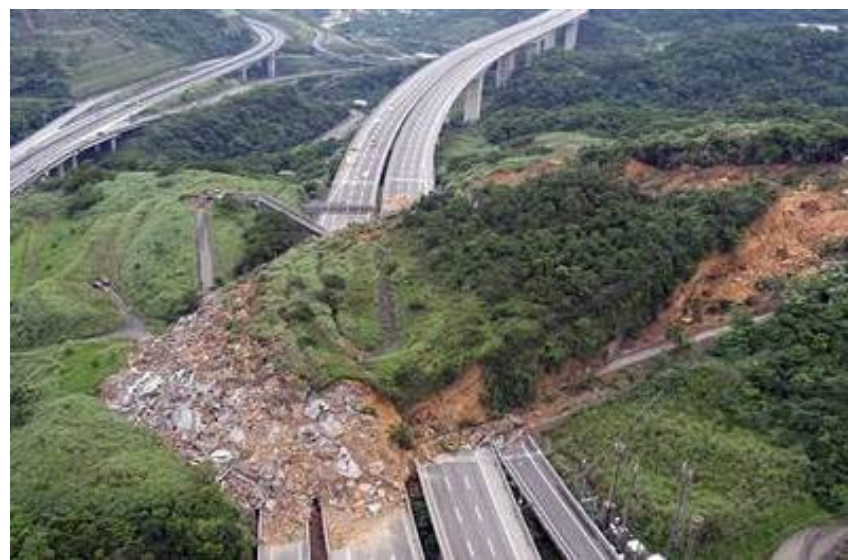

Şekil 1. Tayvan'da meydana gelen heyelanın görüntüsü

Geoteknik mühendisleri, bir şevin durumunu değerlendirirken; yüzey ve yer altı sularına, zeminin kayma dayanımı değerlerine dikkat etmektedir. Yüzeyden gelen sular; şev üzerinde bulunan zeminin yer değiştirmesine neden olarak şev topuğunu aşındırabilmektedir. Ayrıca şev yüzeyi üzerinde basınç yaratabilmektedir. Yer altı suyu; su seviyesinin değişmesi, boşluk suyu basıncı ve sızma basıncı ile şevde etkili olmaktadır. Kayma dayanımı parametrelerinin bilinmesi, göçme mekanizmasının belirlenmesinde önemlidir. Şev stabilitesi probleminin çözümü için; sonlu elemanlar, limit denge ve sonlu farklar yöntemi en çok kullanılan hesap yöntemleridir.

Şev stabilitesi problemi olan, yapılan/yapılması planlanan projelerde, problemin güvenli ve ekonomik bir şekilde çözülmesi için konu ile ilgili değerlendirmelere, araştırmalara ve deneyimlere ihtiyaç vardır. Literatürde, geçmişten bugüne konu ile ilgili birçok çalışma olduğu görülmektedir.

Moudabel, şev vakalarını, limit denge ve sonlu farklar yöntemini kullanarak değerlendirmeye almıştır. Farklı yaklaşımlarla hesaplanan güvenlik faktörleri karşılaştırıldığında, limit denge yöntemleriyle hesaplanan güvenlik sayısının sonlu farklar yöntemiyle hesaplanan güvenlik sayısından fazla olduğu ortaya konulmuştur [4].

Taşkıran ve ark., sonlu elemanlar yöntemi ve mukavemet azaltma yöntemiyle, iki boyutlu ve üç boyutlu model üzerinde güvenlik faktörü durumunu incelemiştir. Sonuçlar limit denge analizinden elde edilen güvenlik faktörleri ile karşılaştırılmıştır. Çalışma sonucunda; üç boyutlu ve iki boyutlu şev modelinden farklı güvenlik sayıları elde edilmiştir. Üç boyutlu model üzerinde yapılan hesaplamalarda güvenlik sayısının daha yüksek olduğu görülmüştür. Mukavemet azaltma yöntemi ile hesaplanan güvenlik sayısı değerlerinin ise, limit denge yöntemleri ile hesaplanan güvenlik sayısı değerleri ile uyumlu olduğu sonucuna varılmıştır [5].

Tschuchnigg ve ark., yaptıkları çalışmada bir şeve ait göçmeyi geri analiz yöntemi ile değerlendirmişlerdir. Mukavemet azaltması yöntemi kullanılarak farklı yaklaşımlarla güvenlik faktöründeki değişim incelenmiştir [6].

Neves ve ark., şev stabilitesi problemine yönelik iyileştirme yöntemlerini, sonlu elemanlar ve limit denge metodunu kullanarak değerlendirmişlerdir. Çalışmada, yaygın iyileştirme yöntemleri ve yöntemlerin etkinliğinden bahsedilmektedir [7].

Bol ve ark., üzerinde yol güzergâhı bulunan, yağış etkisiyle stabilitesi bozulan bir şevi denge durumuna getirmek için tasarım yapmışlardır. Limit denge ve sonlu elemanlar yaklaşımını baz alan bilgisayar yazılımlarını kullanarak şev göçmesini önlemeyi ve şev güvenliğini sağlamayı amaçlamışlardır. Şevde, kazıklı iksa sistemi tasarımı ile iyileştirme sağlanmış ve sonuçlar sunulmuştur [8].

Pirone ve Urciuoli, bir şevi stabil hale getirmek amacıyla, Plaxis'te kayma mukavemeti azaltması tekniğini kullanarak $2 \mathrm{D}$ ve $3 \mathrm{D}$ model üzerinde analizler gerçekleştirmişlerdir. Kazıklar arası mesafeye göre kazık ara yüzünde oluşan deplasmanlar ve şevin göçmesi sırasında zayıf tabakanın rolü incelenmiştir. Şevi iyileştirmek için kullanılan kazıkların tasarımına katkı sunan basit grafikler sunulmuştur [9].

Chen ve ark., bir yol inşaatı üzerinde şev stabilitesi problemine ait bir vaka çalışması sunmuşlardır. Bölgesel kayma mukavemeti temsili değerlerini geri analiz yöntemiyle hesaplamışlardır. Çözüm için beton kirişler ile güçlendirilmiş ankraj uygulaması kullanılmıştır [10].

Büyükkağnıcı ve Işık, çalışmaları için farklı özellikteki üç şev stabilitesi vakası seçmişlerdir. Şev stabilitesi analizinde, ülkemizde kullanılan TS 8853 standardı ile Eurocode 7 ve BS 8006 standartlarının başarı oranlarını karşılaştırmıştır. Analizlerde limit denge yöntemleri yanında sonlu elemanlar yöntemi de kullanılmıştır. Çalışma sonucunda şev stabilitesi analizleri için TS 8853 ile limit denge yöntemlerinin Eurocode 7'ye göre daha güvenilir sonuçlar verdiği belirtilmiştir [11].

Alemdağ, bir baraj dolgusunda baraj gövdesinin yükseltilmesinin stabiliteye etkisini, limit denge ve sayısal analiz yöntemleri ile araştırmıştır. Yapılan dinamik ve statik analizler sonucu elde edilen güvenlik sayıları ortaya koyulmuştur. Baraj gövdesine ait stabilite durumu değerlendirilmiştir [12]. 
Huvaj ve Oğuz, son yillarda şev stabilitesi problemlerinin çözümünde popüler olan olasılıksal yöntem üzerinde durmuşlardır. Norveç'te meydana gelen bir heyelan vakası üzerinde analizler gerçekleştirilmiştir. Analizlerde limit denge ve sonlu elemanlar yöntemi kullanılmıştır. Deterministik ve olasıllksal yaklaşım için güvenlik faktörleri, göçme yüzeyleri gibi faktörler karşılaştırılmıştır. Sonuçlar grafikler halinde sunulmuştur, şev güvenliğinde farklı yaklaşımların değerlendirilmesine katkı sağlanmıştır [13].

Göktepe ve Keskin, çalışmalarında desteksiz kazı çalışması sonucu meydana gelen bir heyelan örneğini ele almışlardır. Dilim yöntemleri ve sonlu elemanlar yöntemini baz alan üç farklı bilgisayar yazılımı ile analizler gerçekleştirilmiştir. Farklı yöntemlerle elde edilen güvenlik sayıları karşılaştırılmış ve söz konusu alanın güvenliği değerlendirilmiştir [14].

Onur ve ark., şevlerde güçlendirme çalışması için kullanılan iki farklı metodu (geogrid ve geotekstil ile güçlendirme) laboratuvar ortamında ve Plaxis programı ile kurulan model üzerinde test etmişlerdir. Statik yük altında model üzerindeki deformasyonlar izlenmiştir. Plaxis ve laboratuvar ortamında oluşturulan modellerden benzer sonuçlar elde edilmiş ve geotekstilin geogride göre daha yüksek direç gösterdiği ve şevde daha az deformasyona sebep olduğu sonucuna varılmıştır [15].

$\mathrm{Bu}$ çalışmada ise stabilite problemi olan bir şev vakası incelenmiştir. Çalışma kapsamında,

- Üzerinde bir yol güzergâhı olan şev üzerinde, potansiyel kaymaları araştırarak, şevi güvenli durumuna getiren tasarımın önerilmesi,

- Güvenlik analizi için, iki farklı yöntem ile hesaplama yapan programların sonuçlarının karşılaştırılması amaçlanmıştır.

\section{MALZEME VE YÖNTEM}

Bu çalışmada, üzerinde bir yol güzergâhı bulunan ve stabilite problemi olan bir şev incelenmiştir (Şekil 2). Yapılan incelemeler kapsamında, heyelanın başladığı ve potansiyel kaymaların söz konusu olduğu bölgede arazi ve laboratuvar çalışmaları yapılmışıtır. Çalışmalar neticesinde bölgedeki mevcut zemin tabakaları ve yer altı suyu durumu değerlendirilmiştir. Vakanın meydana geldiği alan ile çevresinin, yeraltı ve yüzey suları bakımından oldukça zengin olduğu görülmüştür. Yeraltı suyu, zeminin kayma dayanımı değerlerinde değişikliklerin meydana gelmesine sebep olurken yarma üzerindeki çatlaklara yüzey sularının dolması kış mevsiminde donma basınçlarının oluşmasına yol açmaktadır. Bu durumun arazi stabilitesini olumsuz yönde etkilediği tahmin edilmektedir.

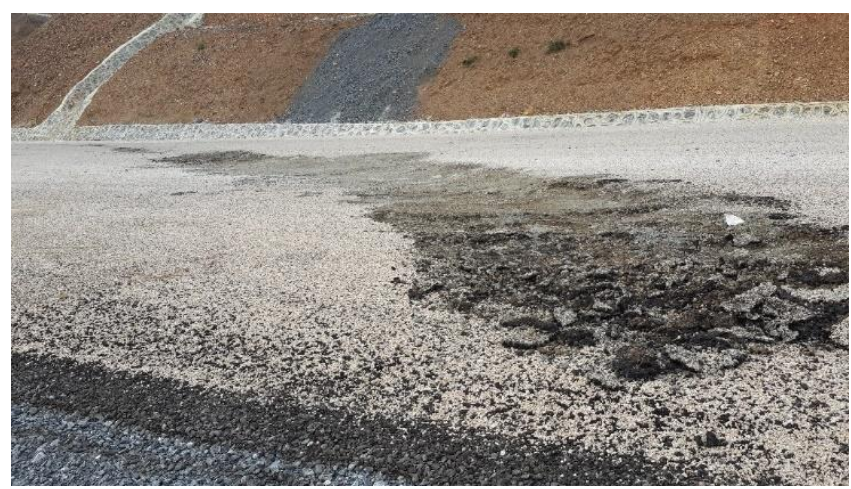

Şekil 2. Heyelanın sebep olduğu yol tahribatı

Şevde denge durumunu sağlamak amacıyla bir dizi çalışma gerçekleştirilmiştir. Özetle; ilk önce, bölgede arazi ve laboratuvar çalışmaları yapıılmıştır. Yapılan çalışmalara göre, zemin özellikleri ve yer altı suyu durumu belirlenmiştir. Daha sonra kaymanın meydana gelmeye başladığı kritik kesitler belirlenmiştir. Kritik kesitler belirlenirken; inklinometre okumaları, zemin özellikleri ve arazi gözlemlerinden yararlanılmıştır. Kritik bölgeler baz alınarak, geri analiz yardımıyla kayma bölgesine ait özellikler belirlenmiştir. Tüm bu verilere göre, sonlu elemanlar yöntemi ve limit denge yöntemleri ile güvenlik analizi yapılmıştır. Son olarak, göçme sınırında olan ve mevcut durumu simüle eden model üzerinde, göçmeyi önleyen tasarım oluşturulmuştur. Hesaplama için, iki farklı program kullanılarak programların avantajlı yönlerinden faydalanılmıştır (Slide programı ile pratik güvenlik analizi yapma, Plaxis programı ile gelişmiş zemin modelleri kullanma gibi). Ayrica her iki programdan elde edilen sonuçların tutarlılığ 1 araştırılmıştır. Hesap aşamaları iki başlık altında açıklanmıştır: Geri analiz ve tasarım hesapları.

\subsection{Geri Analiz}

Bir şev kayarak göçtüğünde, göçme anındaki şev koşulları hakkında geriye dönük bilgi edinilebilir. Şev stabilitesi bozulduğunda, şevde güvenlik sayısı bir (1.0) olarak kabul edilmektedir. $\mathrm{Bu}$ bilgi ışı̆̆ında uygun analiz yöntemi kullanılarak göçme anındaki şev modeli gerçeğe yakın bir şekilde tahmin edilmektedir. Şev; zemin özellikleri, yeraltı suyu, boşluk suyu basıncı, kayma dayanımı parametreleri ve göçme mekanizmalarının kullanıldığı analiz yöntemi ile modellenir. Oluşturulan şev modeli, göçme durumunun daha iyi anlaşıımasına yardımcı olurken uygun tasarımın analizi için esas alınabilir. Bir şev gö̧̧mesi vakasında koşulları belirleyip şeve uygun model oluşturma süreci geri analiz veya geri hesaplama olarak adlandırılır [16].

Geri analizde; göçme anında güvenlik sayısının yaklaşık " 1 " olduğu esas alınır. Hesaplamalar sonucunda elde edilen zemin parametreleri, kayma yüzeyindeki ă̆ırlıklı ortalama kayma dayanımı parametreleridir. Şev modeli üzerinde kaymanın gerçekleştiği bölgede, Gs=1 (Gs: güvenlik sayısı) koşulunu sağlayan "c- $\varphi$ " (c:kohezyon, $\varphi$ :içsel sürtünme açısı) veri çiftleri deneme yanılma yoluyla belirlenir. Şevde farklı yüzeylerde birden fazla göçme meydana geldiyse, 
farklı kesitler için birden fazla "c- $\varphi$ ” zarfi oluşturulur. "c- $\varphi$ " zarfları grafik üzerinde bir araya getirilir ve zarfların kesiştiği noktadan göçme yüzeyine ait kayma dayanımı parametreleri belirlenir [17].

Geri analizde, limit denge yöntemleri ile hesaplama yapılmıştır. Limit denge yöntemleriyle güvenlik sayısı hesaplaması yapılırken göçmenin belirli bir doğrultuda olduğu kabul edilmektedir. Kayma mekanizması arazi şartlarına göre belirlenir. Kaymayı önleyen ve kaymaya neden kuvvetler belirlenir. En olumsuz şartlar göz önünde bulundurularak güvenlik sayısı elde edilir.

Analizlerde, limit denge yöntemlerini baz alan "Slide V.6.0." programı kullanılmıştır. Slide, kaya veya zemin yamaçlarda, farklı geometriye sahip göçme yüzeylerinde, güvenlik sayısı hesabı yapabilmekte ve şevin stabilite olasılığını değerlendirebilmektedir. Ayrıca; harici yükleme, yeraltı suyu ve destek yapıları gibi çeşitli unsurları modellemeye olanak veren iki boyutlu bir programdır. Proje ayarlarından istenilen hesap yöntemi seçilerek güvenlik sayısı hesabı yapilabilmektedir.

Burada analizler, limit denge yöntemlerinden; Bishop, Janbu ve Spencer hesap yöntemleri kullanılarak gerçekleştirilmiştir.

\subsection{Tasarım Hesapları}

Tasarım hesapları kısmında, sonlu elemanlar yöntemi kullanılarak hesaplama yapılmıştır Analizler, sonlu elemanlar yöntemini esas alan Plaxis 2D programı ile gerçekleştirilmiştir.

Hesaplamalarda zemin davranışı olarak Pekleşen Zemin Modeli (Hardening Soil Model) esas alınmıştır. Bu model; kil ve siltler gibi zemin türlerinin yanı sıra, kum ve çakıl türü zeminlerin davranışını da simüle etmek için kullanılabilmektedir [18].

Plaxis ile yapılan analizlerde ağırlık yüklemesi ve mukavemet azaltması yöntemi ile hesaplama yapılmıştır. Mukavemet azaltması yöntemi, Plaxis’te güvenlik analizi için kullanılır, analiz sonucunda şevin mevcut durumuna ait güvenlik sayısı elde edilir. Zemine ait kayma mukavemeti değerleri ( c ve $\varphi$ ) şevde göçme gerçekleşinceye kadar aşama aşama azaltılır ve göçme durumundaki güvenlik sayısı elde edilir [5,14].

Ele alınan modelin geometrisi ve şev içerisinde yer alan zemin katmanları yatay şekilde değildir. Bu nedenle
Plaxis'te analizin ilk aşamasında ăgırlık yüklemesi hesabı yapılmıştır. Ağırlık yüklemesiyle, ilk aşamada zemin kütlesi içinde hiçbir başlangıç gerilmesi oluşmaz. Zemin kütlesinin ilk gerilmeleri, hesaplama modülünde birinci aşamada hesaplanır. Ayrıca, eğer zemin katmanlarından herhangi birinin davranışı drenajsız olarak modellenirse, bu aşamada, "Drenajsız davranışı yoksay" (Ignore undrained behavior) seçeneği seçilmelidir. Bunun sebebi ise, başlangıç aşamasında, dışarıdan bir yük olmadığında ve model geometrisinde hiçbir değişiklik yapılmadığında, zemin davranışının drenajlı durumda olmasıdır [19]. Daha sonra gerçek inşaat aşamaları modellenir ve güvenlik sayısı hesaplanır. Tasarım hesaplarında; zemin davranışını yansıtan model seçimi ve Plaxis'te düzlemsel olmayan zemin tabakaları için izlenen hesap adımlarına dikkat edilmiştir. Buna göre, Plaxis'te zeminlerin yatay durumda olup olmaması durumunda izlenecek hesap adımları Şekil 3 'te gösterilmiştir.

ZEMİN AĞIRLIĞI SEBEBIYLE OLUȘAN BAȘLANGIC̣ GERILMELERI İC̣IN

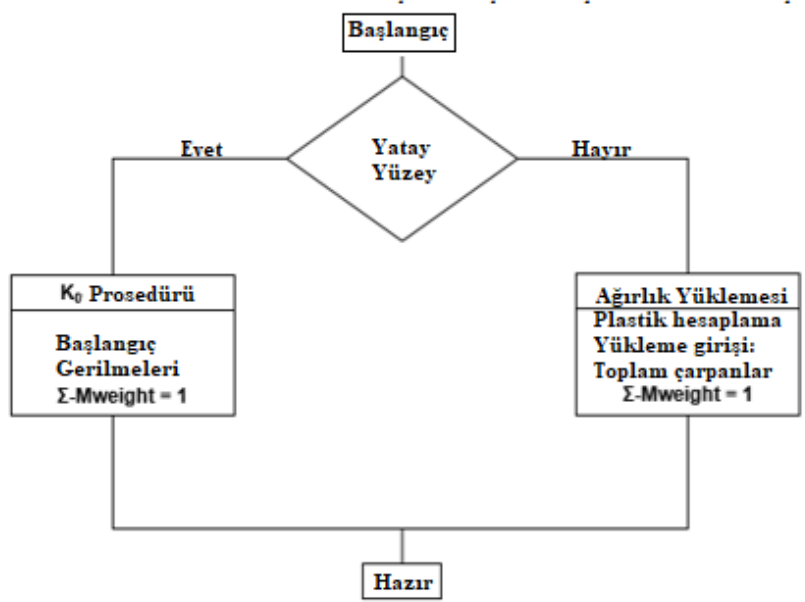

Yatay olmayan yüzey ve yatay olmayan ağırlık tabakaları örnekleri
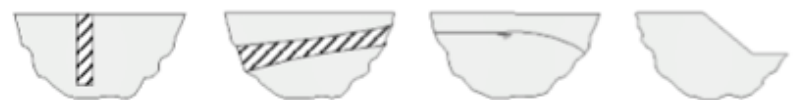

Şekil 3. Plaxis'te zeminin yüzey geometrisine göre hesap adımı şeması [20]

Laboratuvar ve saha çalışmalarından elde edilen veriler, literatürde yer alan ampirik denklemler ve abaklar yardımı ile analiz için gerekli zemin parametreleri belirlenmiştir. Kayma direnci parametreleri deneme yanılma yolu ile geri analiz sonucu belirlenmiştir. Tablo 1'de analizlerde kullanılan zemin özellikleri gösterilmiştir. 
Tablo 1. Analizlerde kullanılan zemin özellikleri

\begin{tabular}{|c|c|c|c|c|c|c|c|c|c|}
\hline Parametre & Sembol & $\begin{array}{l}\text { Mevcut yol } \\
\text { dolgusu } \\
\text { (Qyd) }\end{array}$ & $\begin{array}{l}\text { Yapay } \\
\text { dolgu }\end{array}$ & $\begin{array}{l}\text { Siltli killi } \\
\text { çakı1lı kum } \\
\text {-kumlu } \\
\text { çakı1 }\end{array}$ & $\begin{array}{c}\text { Çakıllli, } \\
\text { siltli, } \\
\text { kumlu kil } \\
- \\
\text { siltli kum }\end{array}$ & $\begin{array}{l}\text { Şist, Grafit } \\
\text { Şist }\end{array}$ & $\begin{array}{l}\text { Çakıllı, } \\
\text { siltli killi } \\
\text { kum }\end{array}$ & $\begin{array}{l}\text { Çakılll, } \\
\text { kumlu, } \\
\text { killi silt }\end{array}$ & $\begin{array}{c}\text { Kayma } \\
\text { düzlemini } \\
\text { temsil eden } \\
\text { tabaka }\end{array}$ \\
\hline $\begin{array}{l}\text { Malzeme } \\
\text { Modeli }\end{array}$ & - & \multicolumn{8}{|c|}{ Hardening Soil Model } \\
\hline $\begin{array}{l}\text { Malzeme } \\
\text { Davranışı }\end{array}$ & - & \multicolumn{8}{|c|}{ Drenajlı } \\
\hline $\begin{array}{c}\text { Kuru Birim } \\
\text { Hacim Ağırlık }\end{array}$ & $\gamma_{\text {dry }}\left(\mathrm{kN} / \mathrm{m}^{3}\right)$ & 18 & 18 & 18 & 18 & 19 & 18 & 18 & 19 \\
\hline $\begin{array}{l}\text { Doygun Birim } \\
\text { Hacim Ağırlık }\end{array}$ & $\gamma_{\text {sat }}\left(\mathrm{kN} / \mathrm{m}^{3}\right)$ & 19 & 19 & 19 & 19 & 20 & 19 & 19 & 20 \\
\hline \multirow{3}{*}{$\begin{array}{l}\text { Elastisite } \\
\text { Modülü }\end{array}$} & $\begin{array}{l}\mathrm{E}_{50}{ }^{\text {ref }} \\
\left(\mathrm{kN} / \mathrm{m}^{2}\right)\end{array}$ & 9600 & 9600 & 54000 & 9600 & 150000 & 40000 & 150000 & 5000 \\
\hline & $\begin{array}{l}\mathrm{E}_{\text {oed }}^{\text {ref }} \\
\left(\mathrm{kN} / \mathrm{m}^{2}\right)\end{array}$ & 9600 & 9600 & 54000 & 9600 & 150000 & 40000 & 150000 & 5000 \\
\hline & $\begin{array}{l}\mathrm{E}_{\mathrm{ur}}{ }^{\mathrm{ref}} \\
\left(\mathrm{kN} / \mathrm{m}^{2}\right)\end{array}$ & 25000 & 20000 & 162000 & 25000 & 450000 & 120000 & 450000 & 15000 \\
\hline Kohezyon & $\mathrm{c}(\mathrm{kPa})$ & 5 & 5 & 2 & 5 & 100 & 5 & 100 & 5 \\
\hline Sürtünme Aç1s1 & $\varphi\left({ }^{\circ}\right)$ & 30 & 30 & 33 & 30 & 15 & 30 & 10 & 17 \\
\hline $\begin{array}{c}\text { Dilatasyon } \\
\text { Açısı }\end{array}$ & $\psi$ & 0 & 0 & 3 & 0 & 0 & 0 & 0 & 0 \\
\hline
\end{tabular}

\section{BULGULAR}

Bu bölümde, sırasıyla, geri analiz ve tasarım hesapları ile ilgili sonuçlara yer verilmiştir. Heyelanlı bölgede, analizleri gerçekleştirmek için üç kritik kesit belirlenmiştir. Arazi üzerinde kayma dayanımı yüksek ve düşük olan farklı zemin tabakları yer almaktadır (Şekil 9.a-10.a). Kayma dairesinin, dayanım parametreleri düşük olan zemin tabakalarından geçtiği beklenmektedir. Bu doğrultuda, bir dizi ön analiz gerçekleştirilmiştir. Kayma dairesinin yerine ve özelliklerine göre farklılık gösteren, güvenlik sınırında olan, şev modelleri değerlendirilmiştir. Kayma yüzeyinin temsili değerlerini ve yerini belirlenmek için; inklinometre okumaları, bölgeye ait tabaka özellikleri, arazi gözlemleri ve limit denge yöntemleriyle yapılan analizden faydalanılmıştır. Daha sonra, belirlenen üç kritik kesit için konu olan şeve ait modeller oluşturulmuştur. Kesitler; A,B ve C kesitleri olarak adlandırılmıştır (Şekil 5). Yol yapısı üzerindeki yükler, $15 \mathrm{kPa}$ 'lı düzgün yayılı yük olarak hesaba dahil edilmiştir. Kaymanın gerçekleşeceği tahmin edilen zayıf yapıdaki zemin katmanı dikkate alınarak, üç farklı kesitte aşağıda görülen kayma mukavemeti veri çiftleri ile analizler gerçekleştirilmiştir (Tablo 2).
Tablo 2. Geri analizde kullanılan kayma dayanımı veri çiftleri

\begin{tabular}{|c|c|c|}
\hline & $\begin{array}{c}C- \\
\text { Kohezyon } \\
\left(\mathrm{kN} / \mathrm{m}^{2}\right)\end{array}$ & $\begin{array}{c}\Phi- \\
\text { Içsel } \\
\text { Sürtünme } \\
\text { Açısl }\left(^{\circ}\right)\end{array}$ \\
\hline \multirow[t]{5}{*}{ A Kesiti } & 1 & 19.2 \\
\hline & 3 & 18.2 \\
\hline & 4 & 17.6 \\
\hline & 5 & 17.0 \\
\hline & 8 & 15.0 \\
\hline \multirow[t]{5}{*}{ B Kesiti } & 1 & 20.3 \\
\hline & 2 & 19.6 \\
\hline & 4 & 17.9 \\
\hline & 6 & 16.1 \\
\hline & 7 & 14.1 \\
\hline \multirow[t]{5}{*}{ C Kesiti } & 1 & 17.0 \\
\hline & 2 & 16.0 \\
\hline & 3 & 15.0 \\
\hline & 4 & 14.0 \\
\hline & 5 & 13.0 \\
\hline
\end{tabular}


Grafikte, kesişen kayma dayanımı zarflarından "c- $\varphi$ " değerinin sırasıyla $5 \mathrm{kN} / \mathrm{m}^{2}-17^{\circ}$ olduğu görülmektedir (Şekil 4).

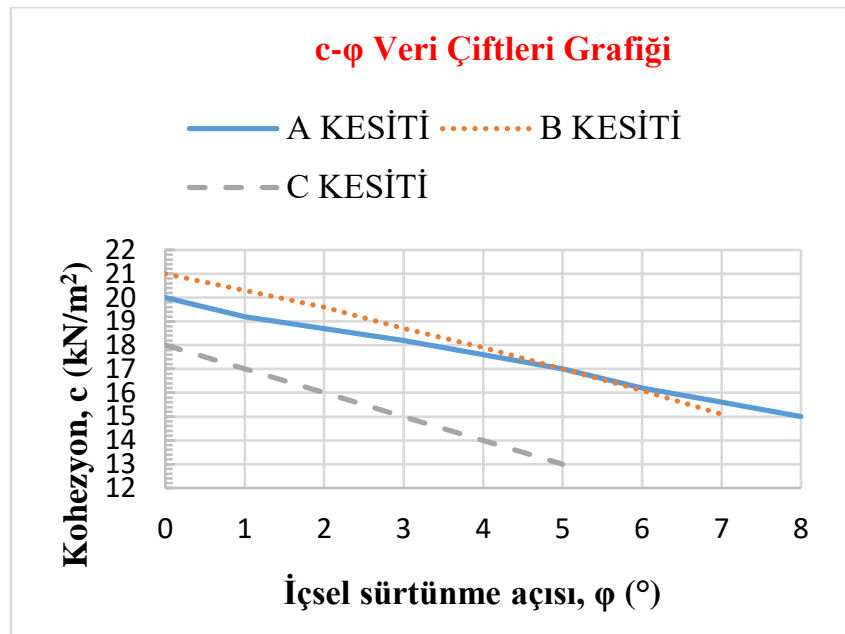

Şekil 4. Kayma dayanımı zarfları grafiği

Aşağıdaki şekillerde, kesitler üzerinde kayma daireleri ve veri çifti grafiğinden elde edilen değerler ile hesaplanan güvenlik sayıları gösterilmiştir (Şekil 6-8). A ve B kesitleri için güvenlik sayısının yaklaşık " 1 " olduğu görülürken $C$ kesitine bu değer 1 'in üzerindedir. $C$ kesitine ait $c-\varphi$ zarfi diğer kesitlere ait veri zarfları ile çakışmamaktadır. Diğer kesitlere kıyasla; $\mathrm{C}$ kesitinde eğim daha düşük, topuk daha yüklü durumdadır. $\mathrm{Bu}$ sebeplerden, $\mathrm{Gs}=1$ değerini sağlayacak kayma mukavemeti veri çiftleri daha düşük değerlerde elde edilmektedir.

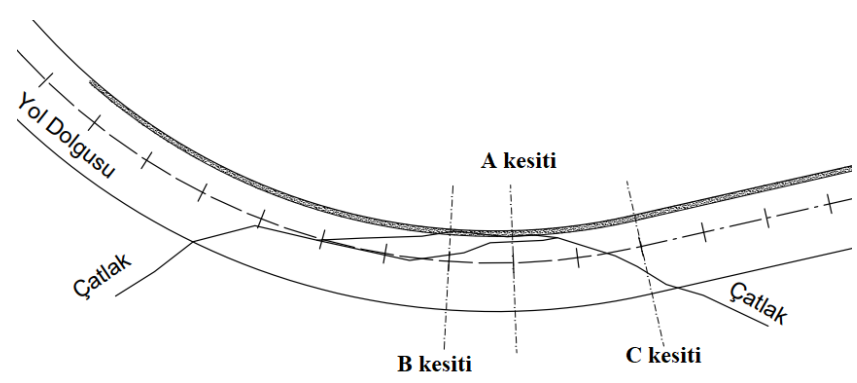

Şekil 5. Yol üzerindeki hasarlı bölge ve kesitlerin yeri

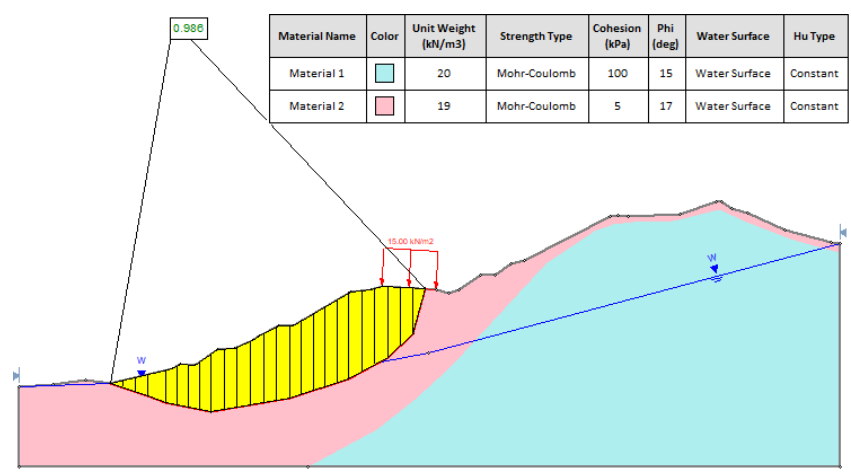

Şekil 6. Şevde A kesitine ait görüntü

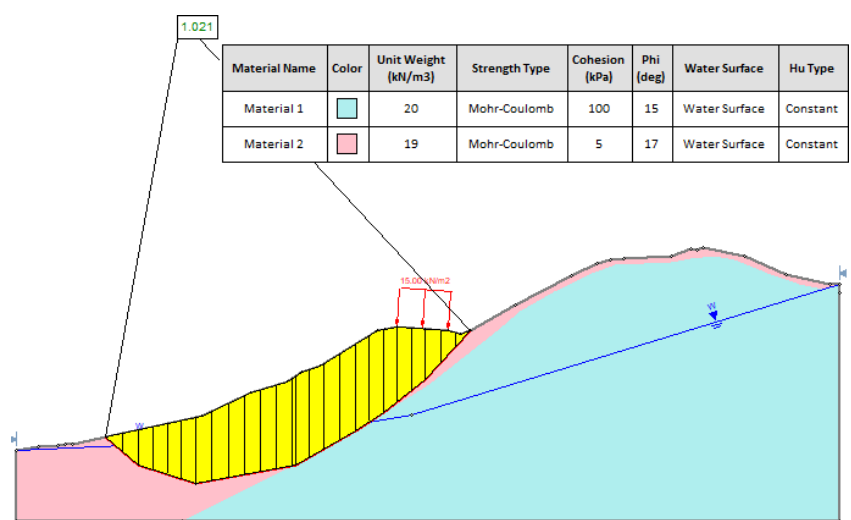

Şekil 7. Şevde B kesitine ait görüntü

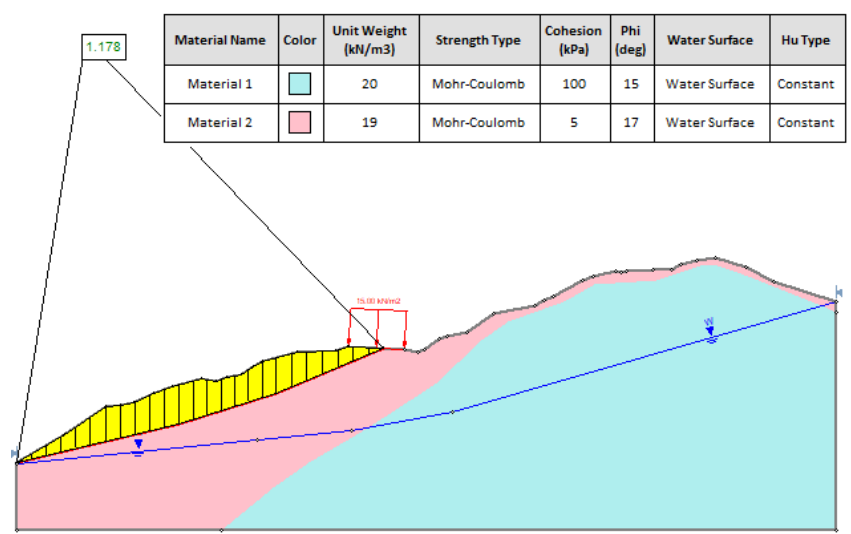

Şekil 8. Şevde C kesitine ait görüntü

Geri analiz sonuçlarında görüldüğü gibi gibi $\mathrm{C}$ kesitine ait kayma dayanımı parametresi değerleri, diğer kesitlere kıyasla daha güvenli yöndedir. Bu nedenle tasarım hesapları, kritik görülen $A$ ve $B$ kesitleri esas alınarak gerçekleştirilmiştir.

Plaxis programında oluşturulan model üzerinde güvenlik analizi tekrarlanmış ve güvenlik sayısı hesaplanmıştır. Analiz sonucunda; A kesiti için güvenlik sayısı, 1.067 olarak elde edilmiştir. Sonuç, Slide programından elde edilen çıktılar ile uyumludur. Sistem göçme sınırındadır; zemin tabakaları özellikleri, kayma dairesi ve özellikleri göçme sınırında olan şevin davranışını yansıtmaktadır.

Göçmeyi engelleyecek durum için birçok analiz yapılmış farklı alternatifler düşünülmüştür. Uygun tasarım, kesitin iki farklı noktasına kazık yapımı ile elde edilmiştir. Kesitin farklı iki noktasına kazık yapıldığında şev güvenliği artmış ve güvenlik sayısı 1.5 değerine yaklaşmıştır. Kazık ile iyileştirme için ekonomik ve güvenli sonucu; $25 \mathrm{~cm}$ arayla yapılan, çapı $1.20 \mathrm{~m}$ ve boyu 30m olan kazıklar sağlamıştır. İnşaat aşamaları dikkate alınarak güvenlik analizi gerçekleştirildiğinde güvenlik faktörünün 1.46 olduğu görülmüştür (Şekil 9).

Tablo 3'te, her iki kesit için hesaplamalarda kullanılan kazık boyutları ve kazık malzeme parametreleri yer almaktadır 
Tablo 3. Tasarımda kullanılan kazık boyutları ve kullanılan parametreler

\begin{tabular}{|l|l|}
\hline $\begin{array}{l}\text { Kazık Boyutları ve Kullanılan } \\
\text { Parametreler }\end{array}$ & Değeri \\
\hline Çap $(\mathrm{m})$ & 1.20 \\
\hline Boy $(\mathrm{m})$ & 30 \\
\hline Malzeme Modeli & Elastik \\
\hline Normal Rijitlik- EA' $(\mathrm{kN} / \mathrm{m})$ & 23399449 \\
\hline Eğilme Rijitliği EI' $(\mathrm{kNm} / \mathrm{m})$ & 2105950 \\
\hline Ağırlık w' (kN/m/m) & 5 \\
\hline Poisson Oranı v & 0.20 \\
\hline
\end{tabular}
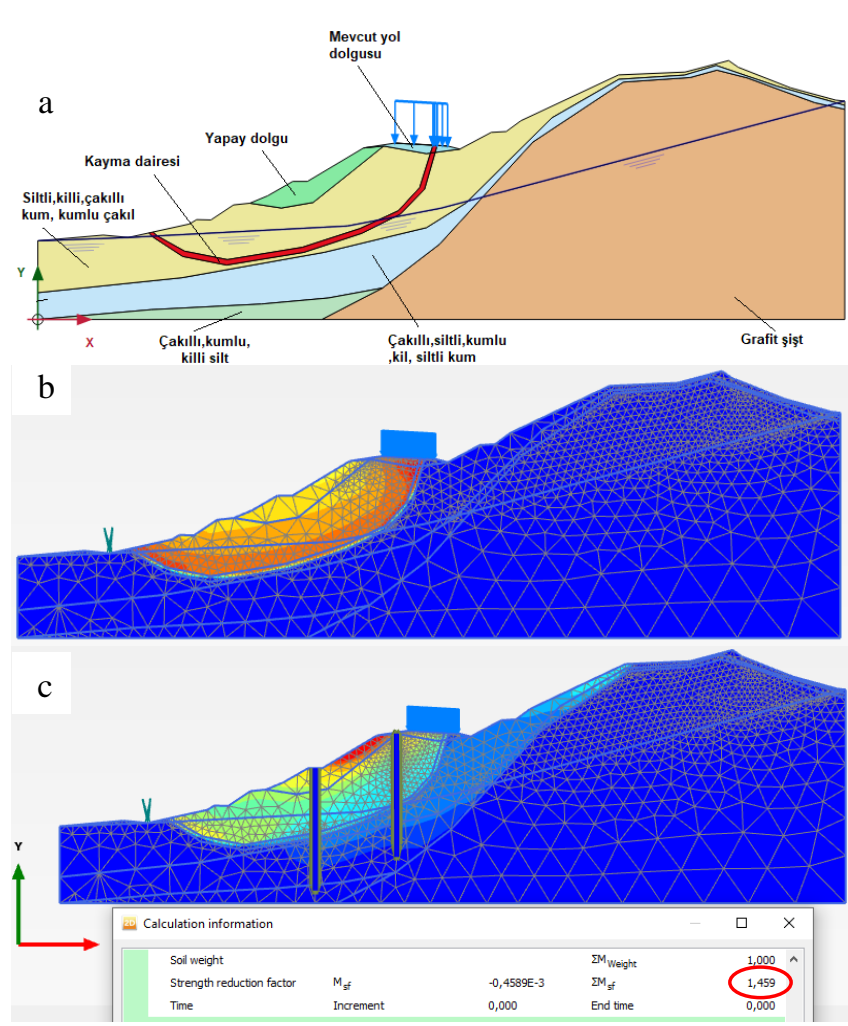

Şekil 9. a) A kesitinde zemin tabakaları, b) A kesitine ait mevcut durum analiz sonucu, c)A kesitine ait tasarım ve güvenlik sayısı

B kesiti için de Plaxis programında oluşturulan model üzerinde güvenlik analizi yapılmış ve güvenlik sayısı hesaplanmıştır. B kesiti için güvenlik sayısının, 1.041 olduğu görülmüştür Sonuç, Slide programından elde edilen çıktılar ile uyumludur. Sistem göçme sınırındadır; zemin tabakaları özellikleri, kayma dairesi ve özellikleri göçme sınırında olan şevin davranışını yansıtmaktadır.

Göçmeyi engelleyecek durum için birçok analiz yapılmış farklı alternatifler düşünülmüştür. A kesitinde olduğu gibi, uygun tasarım, kesitin iki farklı noktasına kazık yapımı ile elde edilmiştir. Kesitin farklı iki noktasına kazık yapıldığında şev güvenliği artmış ve güvenlik sayısı 1.5 değerine yaklaşmıştır. Kazık ile iyileştirme için ekonomik ve güvenli sonucu; $25 \mathrm{~cm}$ arayla yapılan, çap $1.20 \mathrm{~m}$ ve boyu $30 \mathrm{~m}$ olan kazıklar sağlamıştır. İnşaat aşamaları dikkate alınarak güvenlik analizi gerçekleştirildiğinde, güvenlik faktörünün 1.41 olduğu görülmüştür (Şekil 10).
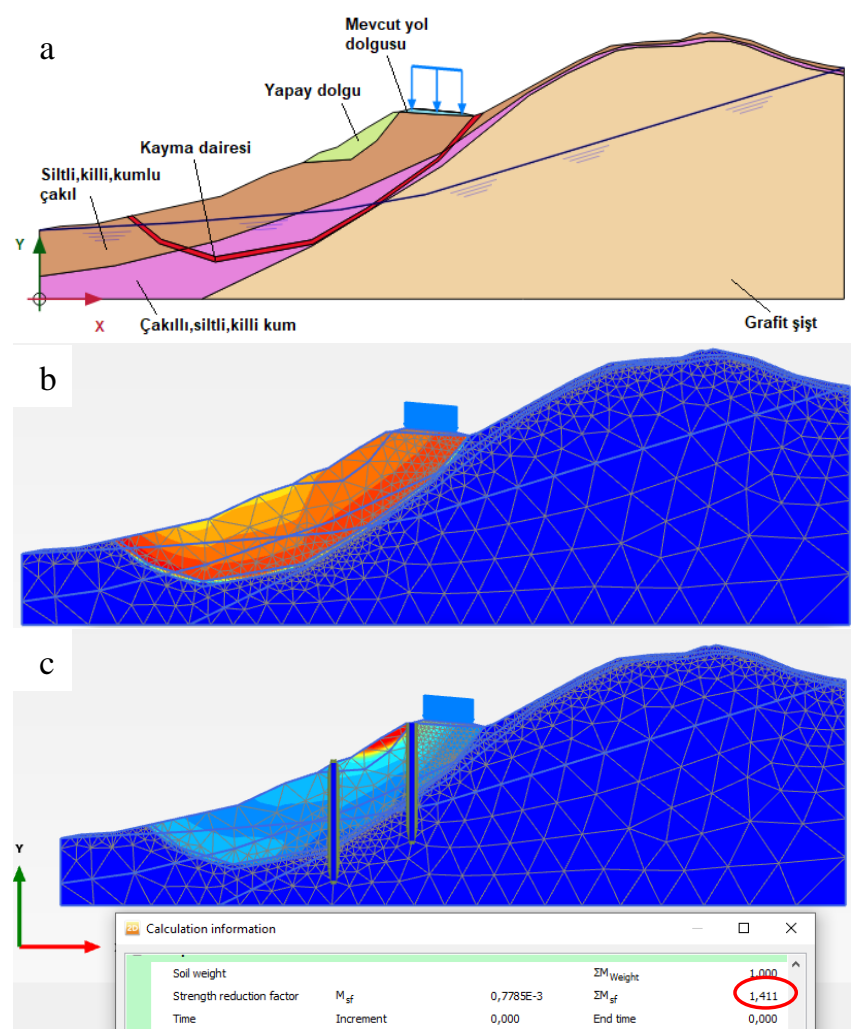

Şekil 10. a) B kesitinde zemin tabakaları, b) B kesitine ait mevcut durum analiz sonucu, c) B kesitine ait tasarım ve güvenlik sayısı

Her iki kesitte de, kazıklar yol ekseninden eşit uzaklıktaki noktalara yerleştirilmiştir. Analizlerde ekonomik faktörler de dikkate alınarak kazık uçlarının, dayanımı yüksek olan zemin tabakasına soketlenmesine dikkat edilmiştir. Analiz sonuçları aşağıda özetlenmiştir (Tablo 4)

\section{Tablo 4. Analiz Özeti}

\begin{tabular}{|l|l|l|l|}
\hline \multirow{3}{*}{ Kesit } & \multicolumn{3}{|c|}{ Analiz Sonucu } \\
\cline { 2 - 4 } & $\begin{array}{l}\text { Doğal şev için güvenlik } \\
\text { sayıs1 }\end{array}$ & $\begin{array}{l}\text { Kazık ile } \\
\text { iyileştirmeden } \\
\text { sonra güvenlik } \\
\text { sayıs1 }\end{array}$ \\
\cline { 2 - 5 } & Slide & Plaxis & Plaxis \\
\hline A & 0.986 & 1.067 & 1.459 \\
\hline B & 1.021 & 1.041 & 1.411 \\
\hline
\end{tabular}

Drenaj önlemleri alınarak şevi daha güvenli hale getirmek hedeflenmiştir. Uygulanacak drenaj sistemi ile şev yüzeyinde birikebilecek yüzey suları toplanıp drene edilerek şevin dengesine zarar verebilecek durumlar ortadan kaldırılacaktır. Burada, yol üstünde bulunan şevin yol platformu ile kesiştiği yere standart drenaj hendeği yapılması önerilmektedir.

\section{DEĞERLENDİRME VE SONUÇ}

$\mathrm{Bu}$ çalışmada bir şev stabilitesi problemi incelenmiştir. Doğal bir şev üzerinde bulunan yol yapısının heyelandan 
korunması ve göçmeye karşı güvenli duruma getirilmesi amaçlanmıştır. Bölgede yapılan incelemelerden sonra şev üzerinde kritik bölgeler belirlenmiştir. Kritik bölgeler baz alınarak geri analiz yardımıyla kayma bölgesine ait parametreler belirlenmiştir. Geri analizden elde edilen verilerle arazinin mevcut durumu modellenmiştir. Son olarak, güvenlik sayısı hesaplanarak göçmeyi engelleyecek tasarım sunulmuştur. Çalışmada, sırasıyla sonlu elemanlar yöntemi ve limit denge yöntemlerini esas alarak hesaplama yapan "Plaxis 2D ve Slide V.6.0.” programları kullanılmıştır. Her iki programdan elde edilen sonuçların tutarlılığı incelenmiştir.

Sonuç olarak, her iki programda; aynı kesitler üzerinde, aynı kayma daireleri ve kayma dayanımı parametreleriyle yapılan analiz sonuçları karşılaştırıldığında güvenlik analizi sonuçlarının uyumlu olduğu görülmüştür. Ayrıca yapılan hesaplamalar neticesinde, şevi denge durumunda tutacak ekonomik ve güvenli çözüm sunulmuştur. Stabilite problemi olan şev için geoteknik tasarımın esası; kayan kütlenin, iki sıra halindeki fore kazıklarla desteklenmesi ve şevi olumsuz etkileyen yüzey sularının drenajına dayanmaktadır.

$\mathrm{Bu}$ tarz şev stabilitesi problemlerinde, güvenlik durumu ve ekonomik unsurlar göz önünde bulundurularak, kayma potansiyeli yüksek zemin tabakalarının kaldırılması veya tabakanın kademelendirilmesi, ankrajla kazıkların desteklenmesi gibi farklı şev iyileştirme yöntemleri de değerlendirilebilmektedir.

\section{BİLGILENDİRME}

Bu makale Buse Ün'ün "Şev Stabilitesi ve Şev Hareketlerine Karşı Alınacak Önlemler" başlıklı yüksek lisans tezinden hazırlanmıştır.

\section{TEŞEKKÜR}

Arazi ve laboratuvar çalıșmaları konusunda desteklerini esirgemeyen Limit Teknik Araştırma firmasına teşekkürlerimizi sunarız.

\section{KAYNAKÇA}

[1].NBCNews,URL:http://www.nbcnews.com/id/36782187 /ns/weather/t/landslide-buries-cars-cuts-highwaytaiwan/\#.XpQyLTdR2U1 (Erişim zamanı: Nisan, 26, 2010) [2].BBC News URL: https://www.bbc.com/turkce/haberlerdunya-40391372 (Erişim zamanı; Haziran, 24, 2017).

[3]. K. Öztürk, "Heyelanlar ve Türkiyeye Etkileri”, Gazi Üniversitesi, Gazi Eğitim Fakültesi Dergisi, 22(2), 2002.

[4]. O. A. M. Moudabel, "Slope Stability Case Study By Limit Equilibrium and Numerical Methods", Doctoral dissertation, Oklahoma State University, Libya, 2013.

[5]. T. Taşkıran, V. S. Yavuz, ve M. S. Keskin, "Şev stabilitesinin iki ve üç boyutlu modeller ile incelenmesi”,
DÜMF Mühendislik Dergisi, 6(1): 1-8, 2015.

[6]. F. Tschuchnigg, , H. F. Schweiger, S. W. Sloan, A. V. Lyamin, and I. Raissakis, "Comparison of finite-element limit analysis and strength reduction techniques". Géotechnique, 65(4): 249-257, 2015.

[7]. M. Neves, V. Cavaleiro, and A. Pinto, "Slope Stability Assessment and Evaluation of Remedial Measures Using Limit Equilibrium and Finite Element Approaches," Procedia Engineering, vol. 143, no. Ictg, pp. 717-725, 2016. [8].E. Bol, S. Sert, and A. Özocak, "Kazıklı iksa sistemi ile şev duraylılığının sağlanması Ensuring slope stability with piled retaining system," vol. 21, no. 5, pp. 860-870, 2017.

[9]. M. Pirone and G. Urciuoli, "Computers and Geotechnics Analysis of slope-stabilising piles with the shear strength reduction technique," Computers and Geotechnics, vol. 102, no. June, pp. 238-251, 2018.

[10]. G. Chen, C. Li, and Q. Fang, "Slope Stabilization Using Back-analysis Method," In IOP Conference Series: Earth and Environmental Science, vol. 332, no. 2, p. 022058, IOP Publishing, 2019.

[11]. Büyükkağnıcı, C. Z., ve Işık, N. S., "Şev Duraylılığı Analizlerinde Limit Denge Yöntemleri, Eurocode 7 Ve Bs 8006 Standartlarıyla Hesaplanan Başarı Oranlarının Karşılaştırılması", TÜBAV Bilim Dergisi, 12(2), 18-29, 2019.

[12]. Alemdağ, S., "Toprak Dolgulu Barajlarda Gövde Duraylılığının Limit Denge Ve Sayısal Analiz Yöntemleri İle Değerlendirilmesi: Türkiye'den Bir Atık Barajı Örneği", Gümüşhane Üniversitesi, Fen Bilimleri Enstitüsü Dergisi, 6(2), 157-173, 2016.

[13]. Huvaj, N., and Oğuz, E. A., "Probabilistic slope stability analysis: a case study", Sakarya Üniversitesi, Fen Bilimleri Enstitüsü Dergisi, 22(5), 1458-1465, 2018.

[14]. Göktepe, F., and Keskin, I., "A comparison study between traditional and finite element methods for slope stability evaluations", Journal of the Geological Society of India, 91(3), 373-379, 2018.

[15]. Onur, M. I., Tuncan, M., Evirgen, B., Ozdemir, B., and Tuncan, A., "Behavior of soil reinforcements in slopes. Procedia engineering", 143, 483-489, 2016.

[16]. J. M.,Duncan, S. G. Wright, , and T. L. Brandon, "Soil strength and slope stability", Canada, John Wiley and Sons, 2014.

[17]. R. Ulusay, "Şevlerin Duraylılığı ve Tasarımı. Kurs Notu", Hacettepe Üniversitesi, Ankara, (yayınlanmamış) 2002.

[18]. Plaxis Reference Manual (Edited by: R.B.J. Brinkgreve, S. Kumarswamy, W. M. Swolfs., F. Foria), Netherlands, Delft University of Technology and Plaxis b.v., 2018.

[19]. T. L. Gouw., "Common Mistakes on the Application of Plaxis 2D in Analyzing Excavation Problems", International Journal of Applied Engineering Research, 9(21), pp 82918311, 2014.

[20]. Plaxis Material Models Manual, Reference Manual. (Edited by R.B.J.Brinkgreve), Netherlands, Delft University of Technology and Plaxis b.v., 2002. 